\title{
Correction to: Methods for identifying 30 chronic conditions: application to administrative data
}

\author{
Marcello Tonelli ${ }^{1 *}$, Natasha Wiebe ${ }^{2}$, Martin Fortin ${ }^{3}$, Bruce Guthrie ${ }^{4}$, Brenda R. Hemmelgarn ${ }^{1}$, Matthew T. James ${ }^{1}$, \\ Scott W. Klarenbach ${ }^{2}$, Richard Lewanczuk ${ }^{5}$, Braden J. Manns ${ }^{1}$, Paul Ronksley ${ }^{6}$, Peter Sargious ${ }^{5}$, Sharon Straus ${ }^{7}$, \\ Hude Quan ${ }^{6}$ and For the Alberta Kidney Disease Network
}

\section{Correction to: BMC Med Inform Decis Mak http://dx.doi.org/10.1186/s12911-015-0155-5}

Following publication of the original manuscript [1], the authors noted several errors in Table 1.

Details of the requested corrections are shown below:

1. Chronic pain - added 3 ICD-10 codes to the far right column that are equivalent to the 3 corresponding codes in the ICD-9 column. Neither the ICD-9 nor the ICD-10 codes are used in Canadian data, but we have corrected this for completeness. We thank Mr. James Wilton for pointing this out.

- G89.0 for 338.0 central pain syndrome

- G89.2 for 338.2 chronic pain

- G89.4 for 338.4 chronic pain syndrome

2. Also for chronic pain - replaced 2 hospitalizations or 2 claims or 2 ACCS in 30 days or less with 2 hospitalizations or 2 claims or 2 ACCS in 30 days or more. We thank Ms. Feng Ye for pointing this out.

3. For Diabetes - replaced the reference to Hux 2005 with a reference to Hux 2002.

4. Myocardial infarction - replaced "1 hospitalization" with "1 most responsible hospitalization". We thank Dr. Ping Liu for pointing this out.
The correct version of Table 1 is included in this erratum with the changes marked in bold.

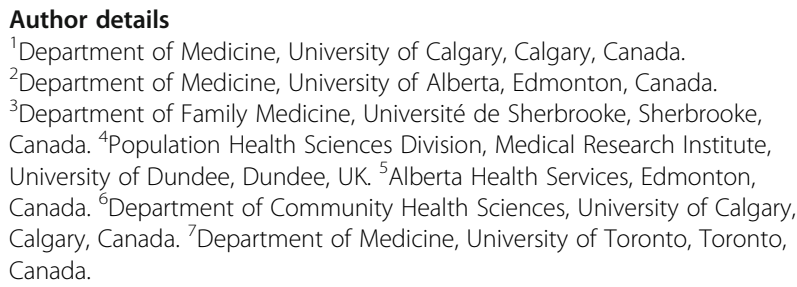

Published online: 04 September 2019

\section{Reference}

1. Tonelli, et al. Methods for identifying 30 chronic conditions: application to administrative data. BMC Med Inform Decis Mak. 2015;15:31. https://doi. org/10.1186/s12911-015-0155-5.

\footnotetext{
* Correspondence: tonelli.admin@ucalgary.ca

${ }^{1}$ Department of Medicine, University of Calgary, Calgary, Canada
}

(c) The Author(s). 2019 Open Access This article is distributed under the terms of the Creative Commons Attribution 4.0 International License (http://creativecommons.org/licenses/by/4.0/), which permits unrestricted use, distribution, and reproduction in any medium, provided you give appropriate credit to the original author(s) and the source, provide a link to the Creative Commons license, and indicate if changes were made. The Creative Commons Public Domain Dedication waiver (http://creativecommons.org/publicdomain/zero/1.0/) applies to the data made available in this article, unless otherwise stated. 
Tonelli et al. BMC Medical Informatics and Decision Making ～(2019) 19:177

Page 2 of 4

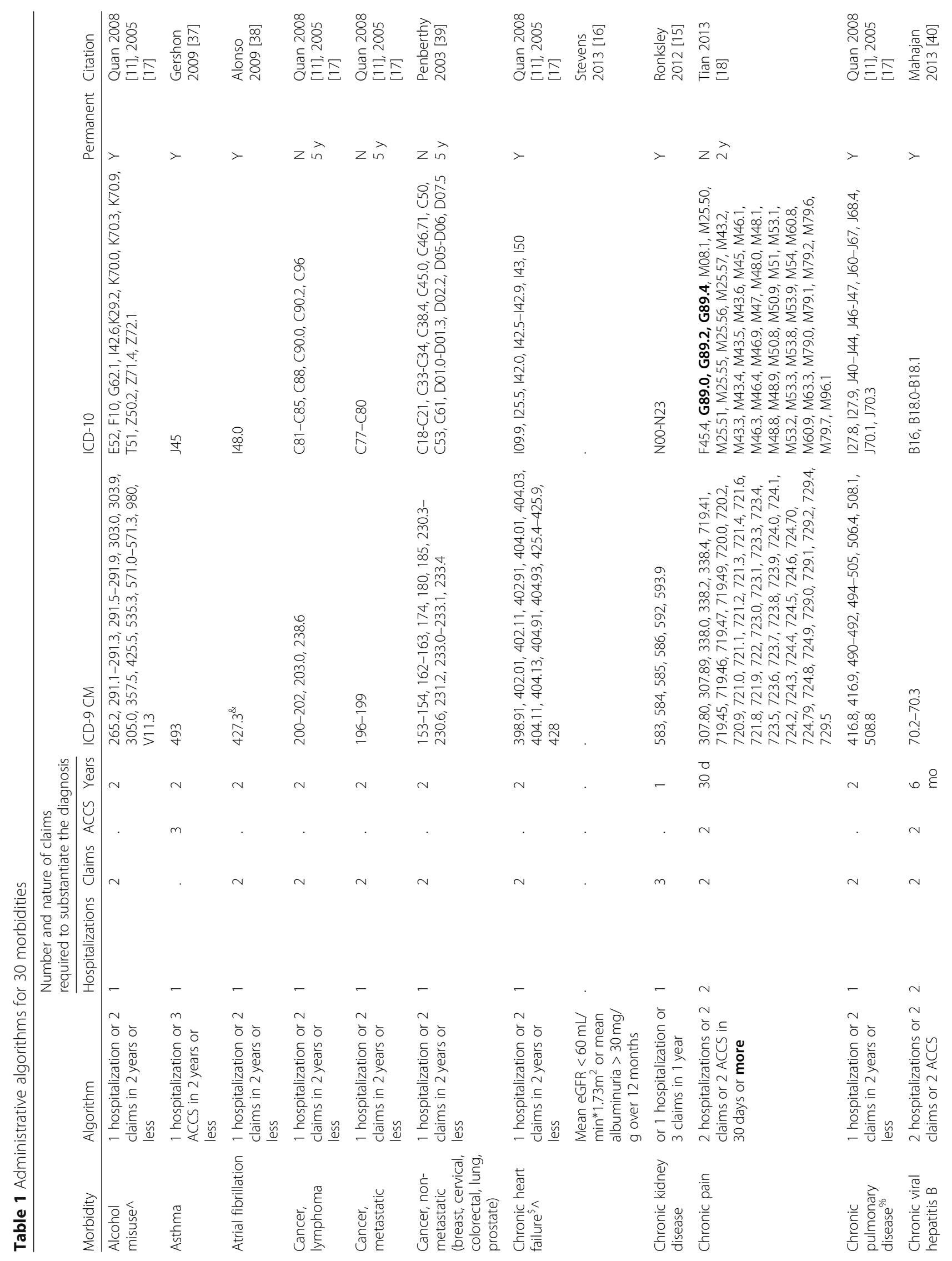


Tonelli et al. BMC Medical Informatics and Decision Making

(2019) 19:177

Page 3 of 4

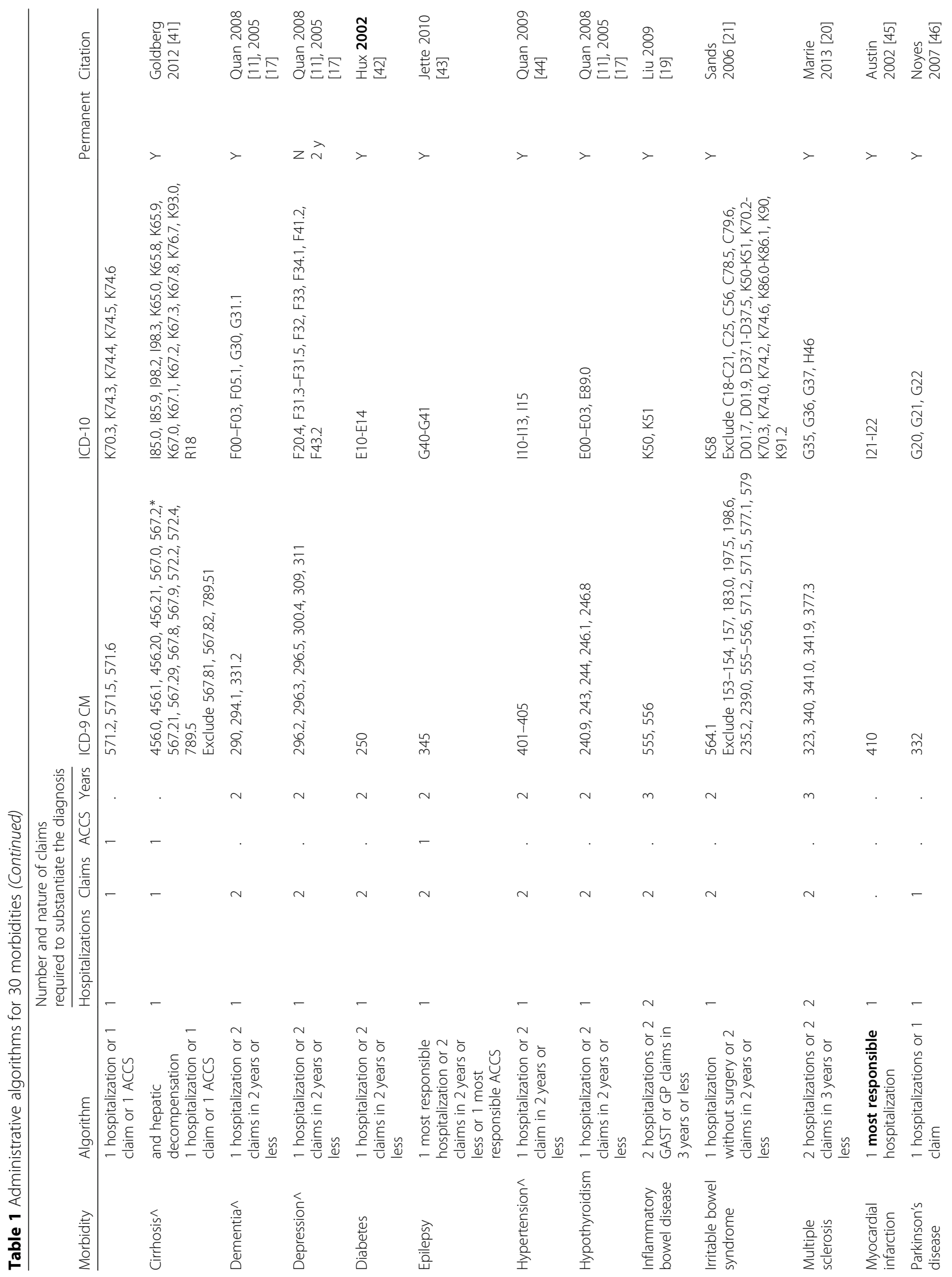




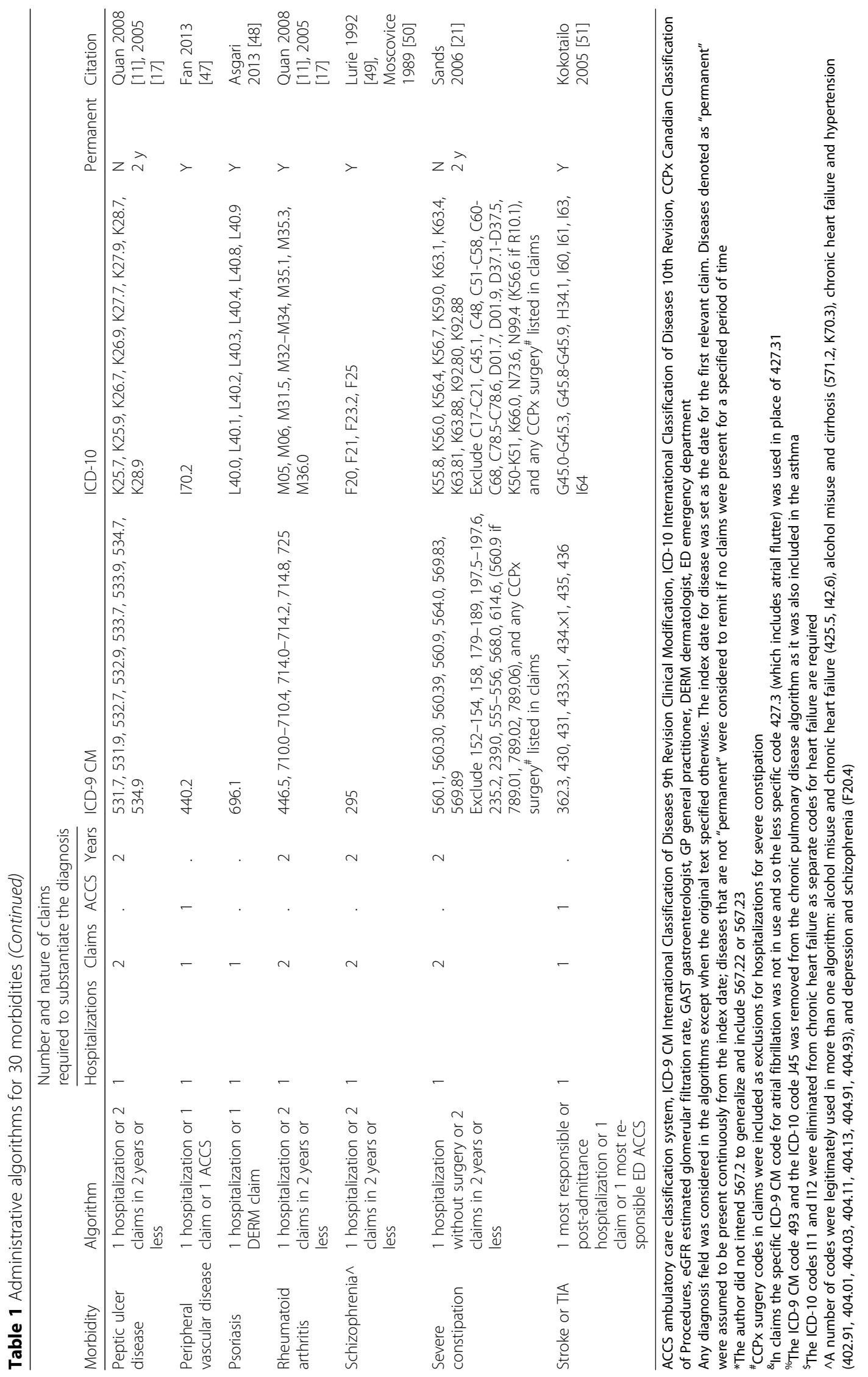

